\title{
Exchanged identities in a complex multiple homicide case. Identification and cause of death
}

\author{
Eugénia Cunha $\cdot$ João Pinheiro $\cdot$ Isabel Pinto-Ribeiro • \\ Duarte Nuno Vieira
}

Received: 13 July 2006 / Accepted: 20 August 2007 / Published online: 14 September 2007

(C) Springer-Verlag 2007

\begin{abstract}
We report a multiple homicide in Angola involving six Portuguese citizens. Immediately after the crime, four bodies were retrieved from the homicide site. Forensic autopsies were allegedly performed by local doctors and three bodies were transferred to Portugal, where they were buried with no extra expertise, presumably identified only by the examinations carried out in Angola. The two remaining bodies, presumably from sub-adults, were only discovered 1 year later. At that time, some bone samples of these two corpses were sent to Portugal. A multidisciplinary team of the National Institute of Legal Medicine (NILM) in Portugal, including forensic anthropologist and pathologists, and forensic geneticist, found out that the bodies were previously misidentified. In fact, the anthropological and genetic examinations on the remains of the two persons showed that they did not belong to a child and an adolescent but instead to two adult victims, at least one of them was supposed to be buried in Portugal since 1 year. The verification of this misunderstanding led to a series of exhumations, of the three victims previously buried in Portugal. In all, the identities were reconstructed and the cause of death could be established in four of them. A multiplicity of severe traumatic cranial injuries were detected, which were, undoubtedly due to a violent death.
\end{abstract}

\footnotetext{
E. Cunha $\cdot$ J. Pinheiro $\cdot$ I. Pinto-Ribeiro $\cdot$ D. N. Vieira Instituto Nacional de Medicina Legal, Largo da Sé-Nova,

Keywords Identification - Cause of death - Manner of death . Forensic anthropology $\cdot$ Interdisciplinarity $\cdot$ Violent death

\section{Introduction}

An atypical forensic anthropology situation has been observed in the National Institute of Legal Medicine (NILM) of Portugal which illustrates well the variety of situations that forensic anthropology can face [1]. Furthermore, it was particularly rich in terms of parameters for identification and signs of the cause of death, and also a good testimony of how interdisciplinarity, among some forensic sciences, can be used to maximize the quality and quantity of results. In our opinion, these circumstances justify the presentation and detailed discussion of these cases.

In 2001, a group of Portuguese citizens (four adults and two children), was the victim of a massacre in Angola. The composition of the group can be derived from Table 1.

The massacre was perpetrated in an open air site and four bodies were soon retrieved from the crime scene. However, despite intensive searches as claimed by the local authorities, the bodies of the other two victims were not found.

The four bodies retrieved were allegedly subjected to forensic examinations by local forensic pathologists, who made the identifications and established the cause of death. After the autopsies, three of the bodies (identified by local experts as B, D and E) were transferred to Portugal to be buried, while a fourth one (identified as F) remained in Angola. Once in Portugal, they were not submitted to any 
Table 1 A summary of the processes of each of the cases discussed in this study

\begin{tabular}{|c|c|c|c|c|c|c|c|}
\hline Case no. & $\begin{array}{l}\text { Alphabetic } \\
\text { designation }\end{array}$ & Sex & Age & $\begin{array}{l}\text { Identification by } \\
\text { Angolian experts }\end{array}$ & Transfer to Portugal & $\begin{array}{l}\text { Exhumation } \\
\text { In Portugal }\end{array}$ & $\begin{array}{l}\text { final } \\
\text { identity }\end{array}$ \\
\hline 1 & A & M & 3 & A & 3 bones & No & A \\
\hline 2 & B & $\mathrm{F}$ & 29 & $\mathrm{C}$ & Whole body & No & B \\
\hline 3 & $\mathrm{C}$ & M & 14 & B & Whole body & Yes & $\mathrm{C}$ \\
\hline 4 & $\mathrm{D}$ & M & 31 & $\mathrm{E}$ & Whole body & Yes & $\mathrm{D}$ \\
\hline 5 & $\mathrm{E}$ & M & 39 & $\mathrm{D}$ & Whole body & Yes & $\mathrm{E}$ \\
\hline 6 & $\mathrm{~F}$ & M & 59 & $\mathrm{~F}$ & Not transferred & No & $\mathrm{F}$ \\
\hline
\end{tabular}

other examination, being immediately buried by the respective families (Table 1).

Surprisingly, the two missing bodies (A and B, Table 1) were discovered 1 year later, only approximately $500 \mathrm{~m}$ away from the place where the other bodies had been found. By then, the bodies were almost totally skeletonized and some bones were taken from each of the skeletons by local authorities and sent to Portugal for identification.

\section{Case 1}

From one of the skeletonized bodies (presumably A, see Table 1), a set of three bones including the complete mandible and four teeth were sent to the NILM, in Lisbon.

The mandible X-ray showed 10 other non-erupted teeth. Both the osseous and dental age (calcification and eruption) indicated to an age at death of 3 years \pm 12 months [2, 3].

This profile showed a good match with the disappeared child: a 3-year-old boy (A) which was later confirmed by DNA analysis. The DNA amplified from one of the bones was compared with the DNA profile of the mother who lived in Angola (where the body was finally buried). Samples from the presumed mother and son were studied by autosomal STRs and by mitochondrial DNA [4, 5].

None of the bones examined in Portugal exhibited injuries. Because we did not have access to the remaining bones, we were not able to assess the cause of death.

\section{Case 2}

The set of bones taken from the other skeletonized body (presumably C, see Table 1) included a complete left humerus, a complete right fibula and the right half of the mandible. All bones and teeth were compatible with having originated from one individual.

The anthropological profile of the dental and osseous items, suggested a young adult [6], most probably a female [7] (dimension of the head of the humerus [7], presence of septal aperture), with a height of 161-166 cm [8]. This profile was not consistent with that of the missing adolescent, a 14-year-old male (C, Table 1) but it fitted with the 29-year-old female (B, Table 1). A suspicion of exchanged bodies arose. A genetic analysis performed on the two molars proved that they belonged to a female. Hence, both anthropological and genetic analysis was in accordance and proved that we were dealing with a misidentification.

DNA extracted from the teeth matched with putative mother of B (Table 1). Although mtDNA could not be used to definitely identify the corpses, it provided evidence of maternal relationships, by means of amplification of two shorter overlapping fragments and the reconstruction of HV1 and HVII sequences [4]. Furthermore, autosomal STRs were also used for identification [4]. Ultimately, the skeletonized body found 1 year after the massacre was identified as that of the young adult female (B) who was thought to be already buried. With the exception of the mandible (Fig. 1), which was broken in three portions, as a

Fig. 1 Case 2. Mandible and skull of the young female (individual B). Traumatic injuries, both on the skull and mandible, were evident and consistent with a severe blunt trauma

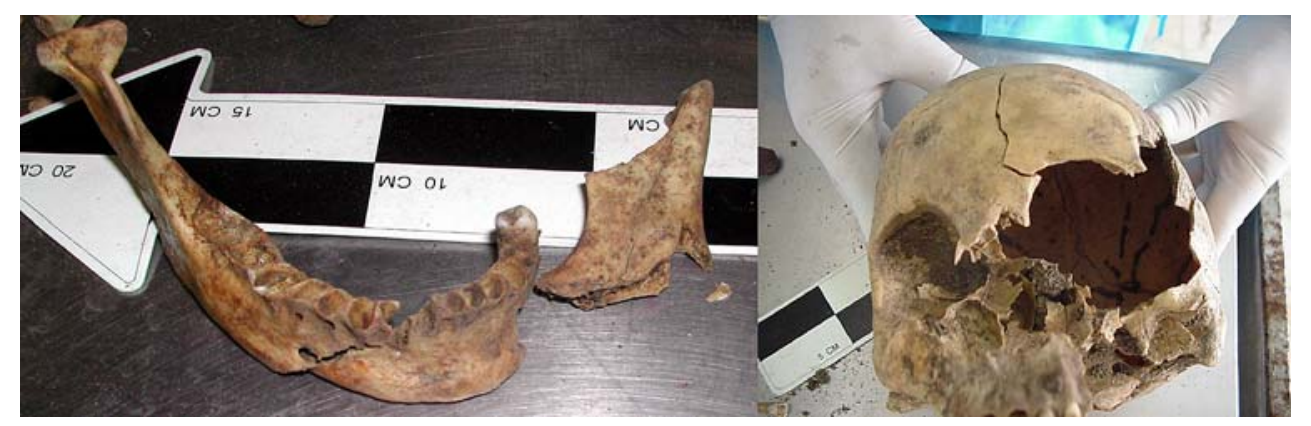


consequence of a traumatic event, the remaining anatomical pieces were free of fractures. Consequently, the remaining skeleton was sent back to Portugal to complete the anthropological and forensic analysis.

The skeleton was well preserved, with the exception of the skull which was severely damaged (Fig. 1). Some hair and clothing were also preserved. All the bones were mixed inside the urn. The bones previously sent to Portugal perfectly matched in this skeleton.

The lost teeth, both those found inside the urn and the ones previously sent, matched in their sockets and the dental chart was achieved.

The anthropological analysis reconfirmed the preceding findings of a young adult female.

Concerning injuries, there was an huge cavity, $140 \mathrm{~mm}$ in its maximal length, on the midfrontal bone (Fig. 1) which also destroyed the left orbit and with radiating lines extended until the skull basis with an associated fracture of the mandibular body. Death was obviously due to severe blunt trauma to the head.

Because there was a misidentification, the verification of the identity of the other three victims previously identified by the African local experts and buried in Portugal for 1 year became mandatory and the three bodies were exhumed after a judicial order.

\section{Case 3}

The first of the three exhumations was performed on the cadaver previously identified as individual B. As expected, instead of her body, another one was found.

The body was partially covered by lime and incompletely clothed. While the thorax was saponified, the limbs were mummified. The skull exhibited a large destruction and was therefore subjected to a thorough anthropological examination. No cuts or interventions related with an eventual previous autopsy were detected.

All findings were suggesting that we were dealing with the adolescent male. Gender diagnosis was derived from pelvic bones analysis. Age range at death was either between 14 and 19 years (epiphysis-diaphysis [2] or between 13 and 14 years (calcification of teeth) [2]. Body length was calculated from the femur length to be $167 \pm$ $3.48 \mathrm{~cm}$ [9]. This biological profile well matched with the adolescent in question $(\mathrm{C}$, Table 1$)$. Dental peculiarities, namely a tooth rotation, once compared with ante-mortem tooth records, verified the identity.

A huge fracture was evident on the right side of the skull with a maximum length of $190 \mathrm{~mm}$ (from the right pterion to the occipital) and a width of $92 \mathrm{~mm}$. Despite severe fragmentation, it was possible to perform cranial reconstruction, where extensive and complex radiating fracture lines were affecting right temporal and parietal as well as the occipital skull.

The fracture pattern was consistent with a blunt force impact, the ring fracture on the skull basis showed that the skull had been forced down onto the vertebral column (Fig. 2). Death was caused by heavy blunt trauma.

\section{Case 4}

The following exhumation was performed on the cadaver originally attributed to the male individual (E, see Table 1).

The body was almost completely mummified and covered with white dust. Besides skin preservation, abundant hair on the thorax, upper limbs and face, namely a beard (Fig. 3) were important clues for preliminary identification. These morphological external traits immediately alerted us that this body had also been misidentified because they were not compatible with the known descriptions of individual E.

Although the skull was still covered with skin, the vast destruction of the left part of the face and of the left mandible (Fig. 3) accounted for the skeletonization of those parts. Of the remaining body, only the left femur was skeletonized.

Two generic factors of identification, gender and age, were retrieved by external macroscopic analysis [3, 6]. Cranial suture closure, sternal ends of the ribs [10] and auricular surface metamorphosis suggested an age range between 25 and 40 years old. The body length was calculated from femur and tibia lengths to be $165 \pm 3.2 \mathrm{~cm}$ [9]. The biological profile was compatible with the person previously designated as D (Table 1).

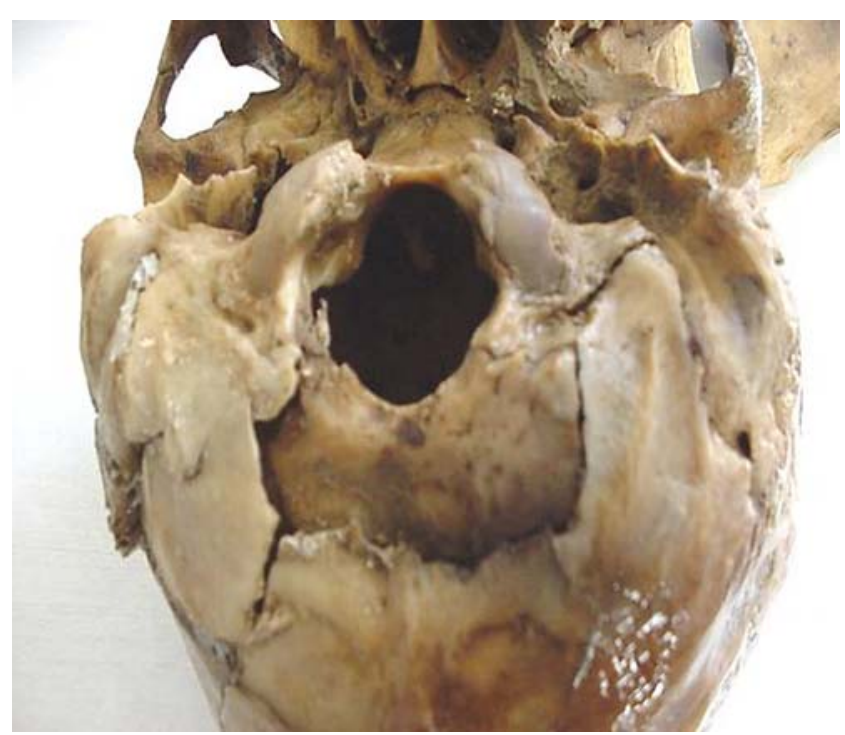

Fig. 2 Ring fracture on the skull basis (case 3) indicating that the skull was forced down onto the vertebral column 
Fig. 3 Case 4. Entry wound on the occipital with the corresponding radiating pattern. The massive destruction of the left facial compound was consistent with the exit wound. Note the fractured mandible as well as the preservation of the beard which was useful for identification

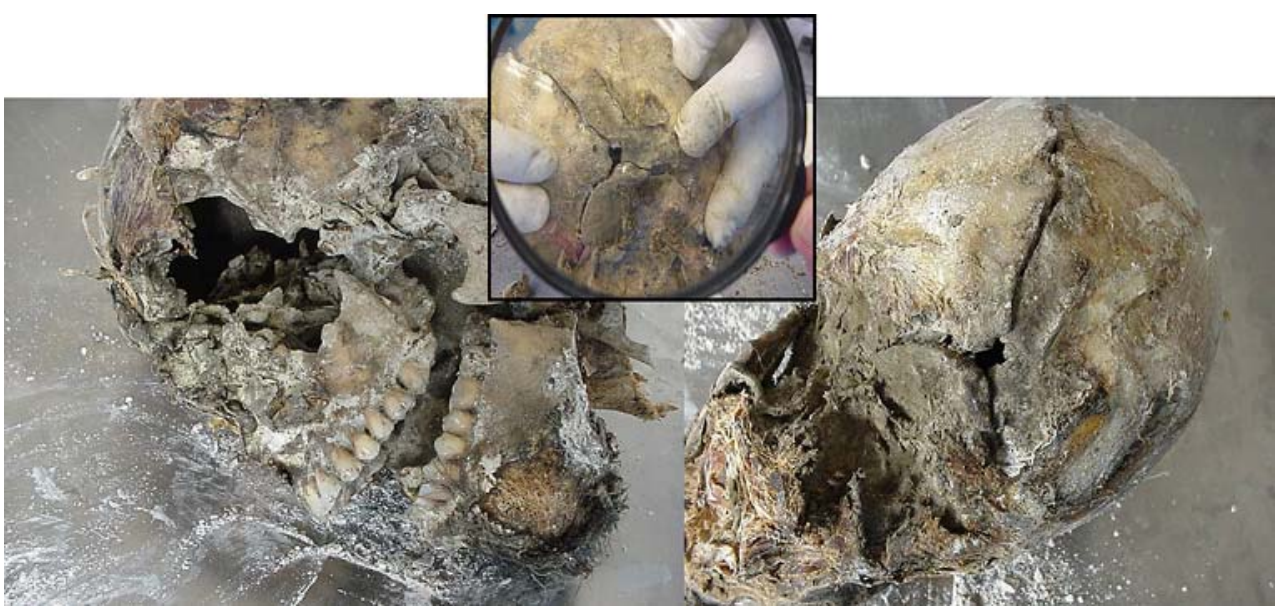

The dentition was in a very good state of preservation permitting a reliable odontogram which was later compared with the ante-mortem data for person D (Table 1). A quite good match was obtained and genetic analysis confirmed the identification.

Facial bones were so severely fractured that they had been shattered into small pieces. It was possible to identify a bullet hole in the occipital where the inward bevelling of the bone was consistent with the entry wound (Fig. 3). This wound was the starting point of a complex radiating pattern which extended into the face and skull basis (Fig. 3). The left part of the mandibular body was also fractured and disarticulated. Furthermore, the upper part of the right

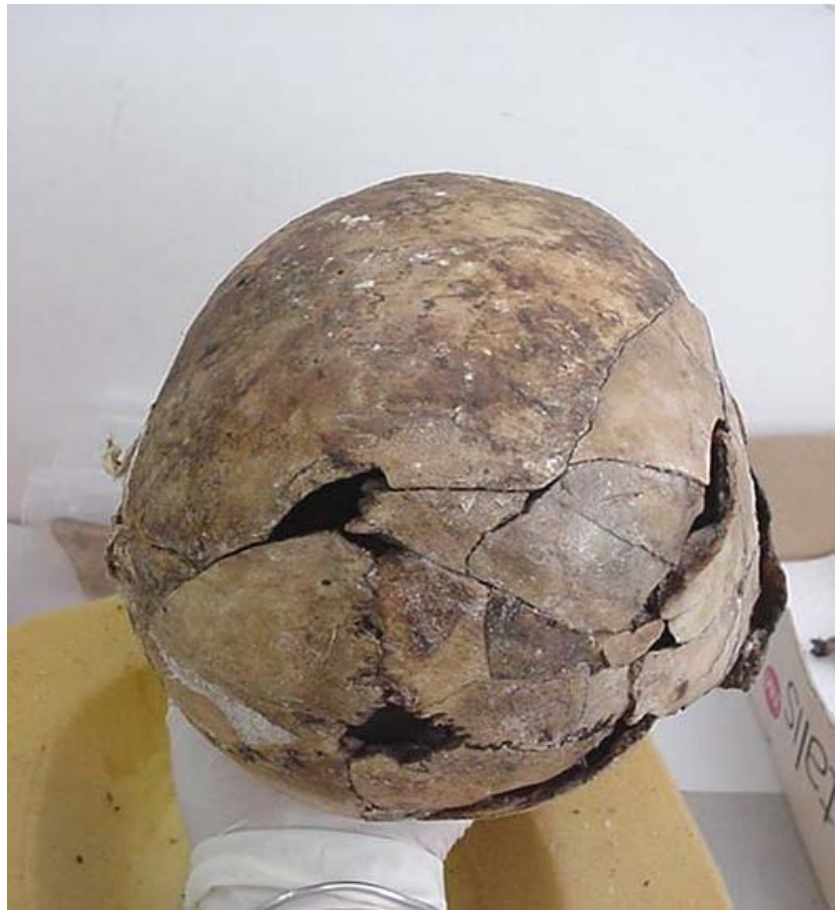

Fig. 4 Case 5. The skull after the meticulous reconstruction with the hole characteristics which corresponded to a previous wormian bone (the lambda one). Note the fractures pattern corresponding to perimortal blunt trauma, which probably determined the death maxilla was also disarticulated. The fracture pattern of the facial complex was compatible with a bullet exit wound and the cause of death was given as a gunshot wound to the head, from the back.

\section{Case 5}

This cadaver had originally been designated as to person D, but since this person was now identified (case 4 ) and other cadavers as well, there only remained two possibilities: either $\mathrm{E}$ or F (Table 1).

The body was not fully skeletonized, the skin was preserved, head and extremities were mummified, and the whole body was covered by a thick layer of white dust (lime). The thorax was skeletonized. A complex fracture of the skull was noted with more than 30 small bone pieces. The skull was difficult to reconstruct, but finally a relatively complete restoration was achieved (Figs. 4 and 5).

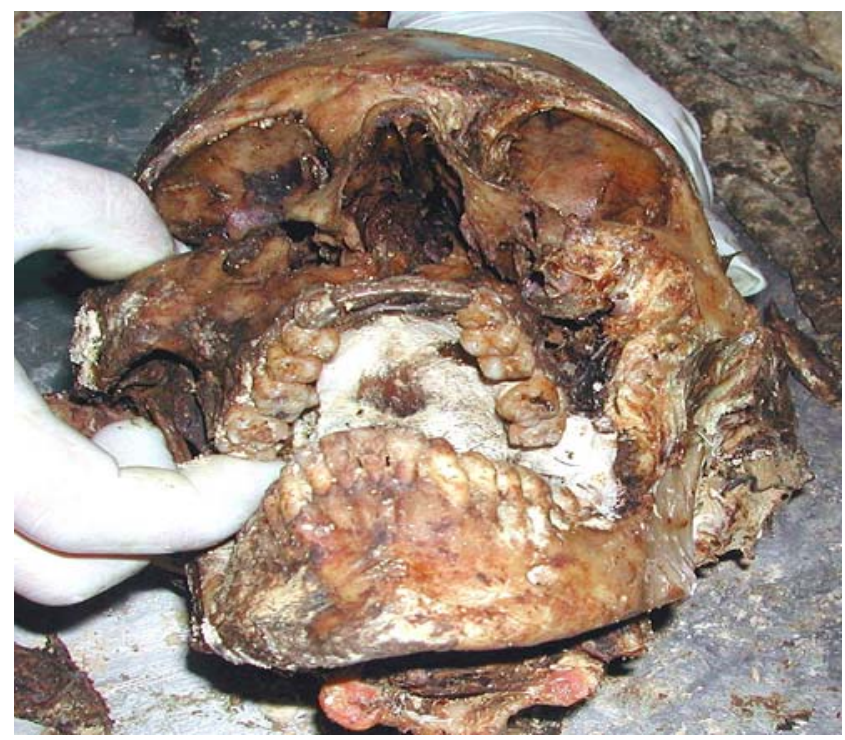

Fig. 5 Case 5. Frontal view of the skull where the anterior dental plaque, a key clue for identification, is visible 
Sex diagnosis was easily made by the external morphology as being a male [3]. Age at death was further estimated on the basis of the sternal end of the fourth rib which indicated to a young adult [6], and the body length was calculated from the femur to be $176 \pm 3.48 \mathrm{~cm} \mathrm{[9].}$

Ante-mortem dental records of individual $\mathrm{E}$ matched with this cadaver. Later, the genetic profile of this victim was compared with presumed family members and this comparison confirmed that we were dealing with person E.

This individual displayed massive skull destruction. With the cranial reconstruction, it was possible to observe multiple radiating and concentric fracture lines affecting the parietal, temporal and occipital bones (Fig. 4) corresponding to three areas of impact by blunt forces.

\section{Case 6}

This was the only body not transferred to Portugal (f); therefore, it was never examined and the identification was made by exclusion.

\section{Final comments}

The resolution of these cases highlight the need and importance of working in interdisciplinary teams, with highly decomposed or almost skeletonized cases, where both identification and manner of death must be achieved, as stated by diverse authors [1, 11-15]. Investigative approaches to human identification are increasingly multidisciplinary in nature $[11,13,16]$.

The specific interrelation between forensic anthropology and genetics is particularly well illustrated. While some of the benefits of genetic analysis are unique, a genetic profile can not provide data on some of the essential parameters of the biological profile, such as age at death and stature [13, 17]. In all cases, it was the biological profile given first by the forensic anthropologist, which raised the hypothesis of an identity exchange. Furthermore, anthropology guided the genetic investigation, namely by a cautious sample selection, precluding doubling the samples from a same body, avoiding waste of time and money [16]. Without a biological profile given by the anthropological examination, the results of the DNA tests could be useless [13].

With respect to the manner of death, despite severe fragmentation of the skull, we were able to associate the lesions with a violent manner of death and to differentiate between gunshot (one case) and blunt force injuries (three cases). In all the cases, the injury pattern, namely the sharpness of the lesion margins, the small fragments of bone attached to the fracture margins and the complete absence of any kind of osteogenic response, indicated that all the fractures occurred at the time of death. However, despite having been killed in the same incident, different weapons were used to cause death. All the features described illustrate the extreme violence used to cause these deaths.

Furthermore, during the examination the team of forensic anthropologist and forensic pathologist was able to demonstrate that no autopsies, or any other type of professional forensic examinations, were previously performed in the country where the crime had been committed as stated by the local authorities.

Hence, these cases are offered as examples of how important it is for a country to have legislation for an obligatory second autopsy in all cases where death of their citizens had occurred abroad.

Last but not the least, we would like to underline the social benefit that forensic anthropology and forensic pathology can both provide to the community, as pointed out previously [18, 19], by returning corpses to their rightful families and clarifying the way in which relatives were murdered, a paramount issue for the psychological recovery of relatives after such a severe trauma.

\section{References}

1. Cunha E, Pinheiro J (2007) Forensic anthropology in Portugal: from current practice to future changes. In: Brickley M, Ferllini R (eds) Forensic anthropology. Case studies from Europe. Charles C. Thomas, Springfield, pp 38-57

2. Schueur L, Black S (2000) Developmental juvenile osteology. Academic Press, San Diego

3. Ubelaker D (1989) Human skeletal remains, 2nd edn. Taraxacum, Washington DC

4. Cruz C, Ribeiro T, Vieira-Silva C, Lucas I, Geada H, Espinheira R (2004) Identification by mtDNA of exchanged human body remains. International Congress series 1261, pp 374-376

5. Gusmão L, Butler JM, Carracedo A et al (2006) Commission of the International Society of Forensic Genetics (ISFG): an update of the recommendations on the use of Y-STRs in forensic analysis. Int J Legal Med 120(4):191-200

6. Olze A, Bilang D, Schmidt S, Wernecke KD, Geserick G, Schmeling A (2005) Validation of common classification systems for assessing the mineralization of third molars. Int $\mathrm{J}$ Legal Med 119(1):22-26

7. Wasterlain S, Cunha E (2000) Comparative performance of femur and humerus epiphysis for sex diagnosis. Biom Hum Anthropol 18(1-2):9-13

8. Olivier G, Tissier G (1975) Détermination de la stature féminine d'après les os longs des membres. Bull Mém Soc Anthropol Paris 2 XIII:297-306

9. Olivier G, Aaraon C, Fully G, Tissier G (1978) New estimations of stature and cranial capacity in modern man. J Hum Evol 7:512-518

10. Iscan MY (ed) (1989) Age markers in the human skeleton. Charles C. Thomas, Springfield

11. Pinheiro J, Cunha E (2006) Forensic Investigations of corpses in various stages of decomposition: a multidisciplinary approach. In: Schmitt A, Cunha E, Pinheiro J (eds) Forensic anthropology and medicine: complementary sciences from recovery to cause of death. Humana Press, New Jersey, pp 159-196 
12. Ubelaker D (2003) Multidisciplinary approach to human identification in Homicide Investigation: a case study from New York. In: Steadman DW (ed) Hard evidence. Case studies in forensic anthropology. Prentice Hall, New Jersey, pp 46-51

13. Cunha E, Pinheiro J, Vieira DN (2006) Identification in forensic anthropology: its relation with genetics. In: International Congress series 1288, pp 807-809

14. Cattaneo C, Angelis D, Porta D, Grandi M (2006) Personal identification of cadavers and human remains. In: Schmitt A, Cunha E, Pinheiro J (eds) Forensic anthropology and medicine: complementary sciences from recovery to cause of death. Humana Press, New Jersey, pp 359-382

15. Cattaneo C, Ritz-Timme S, Schutz HW, Waite H, Boormann H, Grandi M, Kaatsch HJ (2000) Unidentified cadavers and human remains in the EU. Int J Legal Med 113(3):N1-N3
16. Budimlija Z, Mechthild K, Zelson-Mundorff A, Wiersema J, Bartelink E, MacKinnon G, Nazzaruollo B, Estacio S, Hennessey M, Shaler R (2003) World Trade Center human identification project: experiences with individual body identification cases. Croat Med J 44(3):259-263

17. Wurmb-Schwark N, Bosinski H, Ritz-Timme S (2007) What do the $\mathrm{X}$ and $\mathrm{Y}$ chromosomes tell us about sex and gender in forensic analysis? J Clin Forensic Med 14(1):27-30

18. Wright R (1980) Forensic pathology: last stronghold of the autopsy. J Forensic Med Pathol 1(1):57-60

19. Pinheiro J (2006) Introduction to forensic medicine and pathology. In: Schmitt A, Cunha E, Pinheiro J (eds) Forensic anthropology and medicine: complementary sciences from recovery to cause of death. Humana Press, New Jersey, pp $13-38$ 